\title{
Correlação e análise do coeficiente de trilha dos componentes do rendimento de sementes de grama-forquilha
}

\author{
Rodrigo Ramos Lopes ${ }^{1}$, Lúcia Brandão Franke²
}

\footnotetext{
1 Programa de Pós-graduação em Zootecnia, Faculdade de Agronomia, Universidade Federal do Rio Grande Sul

2 Departamento de Plantas Forrageiras e Agrometeorologia da Faculdade de Agronomia/UFRGS, Caixa Postal 15100, 91501-970, Porto Alegre, RS.
}

RESUMO - Objetivou-se com este trabalho, por meio de uma análise de trilha para rendimento de sementes de gramaforquilha (Paspalum notatum Flügge var. notatum), obter informações básicas para utilização em estratégias de manejo para maior produção de sementes e, consequentemente, maior ressemeadura natural, proporcionando, assim, condições para maior persistência da espécie na pastagem. Foram analisadas as seguintes variáveis: número de perfilhos vegetativos, número de perfilhos reprodutivos, número de racemos/inflorescência, número de sementes/inflorescência, peso de mil sementes e rendimento de sementes. A variável que mais se correlacionou com o rendimento de sementes foi o número de perfilhos reprodutivos $(\mathrm{r}=0,94)$, e essa correlação se deu praticamente apenas pelo efeito direto dessa variável. Entre as demais variáveis, destacou-se o número de perfilhos vegetativos, com coeficiente de correlação de -0,83 e efeitos indiretos sobre os demais componentes do rendimento de sementes. O número de perfilhos reprodutivos parece ser a principal característica a ser considerada na busca de maior produção de sementes de Paspalum notatum.

Palavras-chave: componentes do rendimento de sementes, perfilho reprodutivo, perfilho vegetativo, peso de sementes

\section{Correlation and path coefficient analyses of seed yield components in the bahia grass (Paspalum notatum Flügge var. notatum)}

\begin{abstract}
The objective of this work was, through a path analysis of seed yield in Paspalum notatum, to obtain basic information for using in management strategies to improve seed production and consequently, high natural reseeding and a better persistence of the species in the pasture. The following variables were analyzed: number of vegetative tiller, number of reproductive tiller, number of raceme/inflorescence, number of seeds/inflorescence, weight of 1000 seeds and seed yield. The most correlated variable with seed yield was the number of reproductive tiller $(r=0.94)$, and this occurred because its direct effect. Among the other variables, number of vegetative tiller also had a high correlation coefficient $(r=-0.83)$ and indirect effects on the other components. The number of reproductive tiller seems to be the main characteristic to be considered when searching for a higher seed production in Paspalum notatum.
\end{abstract}

Key Words: reproductive tiller, seed weight, seed yield components, vegetative tiller

\section{Introdução}

Inúmeros acessos de Paspalum notatum têm sido incorporados a experimentos agronômicos, devido ao bom valor forrageiro, à rapidez de estabelecimento e a uma densa cobertura do solo. Steiner (2005), testando genótipos de $P$. notatum nativos do Rio Grande do Sul, obteve expressivos valores de produção de matéria seca total (MST), próximas a $14.000 \mathrm{~kg}$ de $\mathrm{MST} / \mathrm{ha}$, provando o potencial produtivo desta espécie nativa, chegando a níveis de produção próximos de cultivares de espécies tropicais introduzidas (Cecato et al., 2000).

A utilização da semente, como veículo de propagação de espécies forrageiras, representa importante marco no desenvolvimento da pecuária nacional, ao promover uma rápida disseminação de novos materiais. A produtividade é um caráter complexo e resultante da expressão e associação de diferentes componentes (Carvalho et al., 2002), tais como, a pureza genética, a sanidade, a qualidade e o vigor das sementes utilizadas. Com a participação dos efeitos do ambiente na manifestação fenotípica, qualquer mecanismo que auxilie o pesquisador a conhecer os efeitos que interagem no comportamento de um caráter permite maior eficiência em sua seleção (Kurek et al., 2001).

O estudo das correlações entre caracteres tem aplicações em praticamente todos os campos de pesquisa. A correlação simples permite apenas avaliar a magnitude e o sentido da associação entre dois caracteres, sem fornecer informações 
necessárias relativas aos efeitos diretos e indiretos de um grupo de caracteres em relação a uma variável dependente de maior importância. A análise de trilha permite o estudo dos efeitos de variáveis independentes sobre uma variável básica, cujas estimativas são obtidas por meio de equações de regressão em que as variáveis são primeiramente padronizadas (Cruz, 2007).

A análise de trilha foi adaptada e vem sendo muito utilizada para investigar as relações entre os componentes do rendimento de sementes em culturas produtoras de grãos (Babar et al., 2007; Aycicek \& Yildirim, 2006; Coimbra et al., 2004). Em plantas forrageiras tem sido usada para avaliar os componentes do rendimento de sementes (Abbott et al., 2007; Sengul, 2006), bem como os componentes da produção de matéria seca (Silva et al., 2008; Adeniji, 2007). Entretanto, ainda são escassos trabalhos dessa natureza envolvendo forrageiras nativas do bioma campos.

Objetivou-se com este trabalho determinar, por meio da análise de coeficiente de trilha, quais variáveis estão envolvidas no rendimento de sementes de $P$. notatum, suas interrelações e importância relativa.

\section{Material e Métodos}

O experimento foi conduzido na Estação Experimental Agronômica da Universidade Federal do Rio Grande do Sul (EEA - UFRGS), no município de Eldorado do Sul ( $30^{\circ} 05^{\prime} 52^{\prime \prime} \mathrm{S}, 51^{\circ} 39^{\prime} 08^{\prime \prime} \mathrm{W}$ e altitude média de $46 \mathrm{~m}$ ), região fisiográfica da Depressão Central do Rio Grande do Sul, cujo clima é do tipo Cfa, subtropical úmido com verão quente, segundo classificação de Köppen. De acordo com Bergamaschi (2003), a precipitação total média anual na EEA situa-se em torno de 1.440 mm, com média mensal de $120 \mathrm{~mm}$. Os eventos meteorológicos registrados durante o período experimental foram obtidos na Estação Meteorológica do Departamento de Plantas Forrageiras e Agrometeorologia/UFRGS, localizada a cerca de $10 \mathrm{~m}$ da área experimental (Figura 1).

O solo da unidade experimental pertence à Unidade de Mapeamento São Jerônimo, classificado como Argissolo Vermelho distrófico típico - Pvd (Streck et al., 2008), foi amostrado em 20 de outubro de 2006 e apresentou as seguintes características químicas: $\mathrm{pH}$ água: 5,6; índice SMP: 6,4; P: 8,1 mg/dm³ $\mathrm{K}: 162 \mathrm{mg} / \mathrm{dm}^{3}$; MO: 1,7\%; $\mathrm{Al}_{\text {troc. }}: 0,0 \mathrm{cmol} / \mathrm{dm}^{3} ; \mathrm{Ca}: 2,6 \mathrm{cmol}_{\mathrm{c}} / \mathrm{dm}^{3} ; \mathrm{Mg}: 1,1 \mathrm{cmol}_{\mathrm{c}} / \mathrm{dm}^{3}$; e CTC efetiva: $6,9 \mathrm{cmol}_{\mathrm{c}} / \mathrm{dm}^{3}$. A área experimental $\left(120 \mathrm{~m}^{2}\right)$ foi corrigida com 2 ton/ha de calcário dolomítico e $200 \mathrm{~kg} /$ ha da mistura $\mathrm{N}-\mathrm{P}_{2} \mathrm{O}_{5}-\mathrm{K}_{2} \mathrm{O}$ 5-20-20 no dia 31 de outubro de 2006. Os cálculos foram feitos baseados na quantidade de potássio recomendada, suprindo os demais

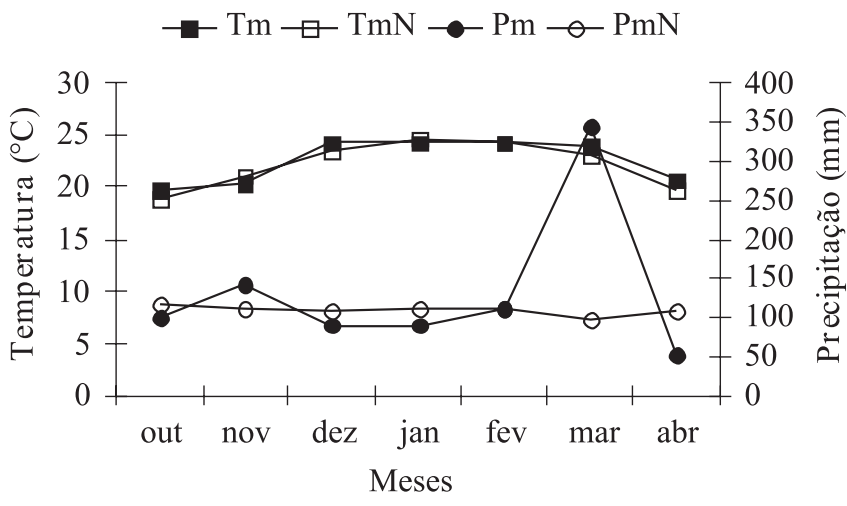

Figura 1 - Temperatura média mensal (Tm) e precipitação pluviométrica mensal $(\mathrm{Pm})$ durante o período experimental (2006/2007) e as normais para a região (temperatura média normal, $\mathrm{TmN}$; precipitação pluviométrica mensal normal, $\mathrm{PmN}$ ).

nutrientes com a adição de 33,3 kg/ha de $\mathrm{N}$ (ureia) e $110,0 \mathrm{~kg} / \mathrm{ha}$ de $\mathrm{P}_{2} \mathrm{O}_{5}$ (superfosfato triplo).

O plantio da planta forrageira foi realizado por mudas, produzidas no outono e mantidas em casa de vegetação durante o inverno. Foram plantadas 63 mudas de $P$. notatum por parcela, com espaçamento de $25 \mathrm{~cm}$ entre linhas e entre plantas. O delineamento experimental foi completamente casualizado, com cinco repetições, em parcelas de 1,5 × 2,0 $\mathrm{m}\left(3 \mathrm{~m}^{2}\right)$, com espaçamento entre parcelas de 0,5 m. Foram avaliados dois ecótipos de $P$. notatum (André da Rocha e Bagual) que foram coletados na Estação Experimental Agronômica da Universidade Federal do Rio Grande do Sul, sendo originários de antigos experimentos com material coletado a campo em excursões realizadas pelo estado.

O acompanhamento do período vegetativo, do florescimento e da produção de sementes foi realizado por meio de amostragens semanais entre 7/11/2006 a 31/3/2007, sendo avaliados: a) número de perfilhos vegetativos $/ \mathrm{m}^{2}$ : contagem direta dos colmos em estádio vegetativo, em áreas de 0,125 $\mathrm{m}^{2}(0,25 \times 0,50 \mathrm{~m})$; b) número de perfilhos reprodutivos $/ \mathrm{m}^{2}$ : contagem direta dos colmos que formaram inflorescências, em áreas de 0,125 m² (0,25 × 0,50 m); c) número de racemos/inflorescência: média do número de racemos de duas inflorescências, escolhidas ao acaso em cada parcela; d) número de sementes/inflorescência: regra de três entre o peso de 1.000 sementes e o peso médio de sementes por inflorescência; e) peso de mil sementes: média da pesagem de oito subamostras de 100 (cem) sementes, multiplicada por 10; f) rendimento de sementes/área: coleta e pesagem das sementes limpas colhidas por ocasião das amostragens semanais, obtendo-se assim o rendimento de sementes por parcela, expresso em gramas. 
A matriz de correlação residual de todas as variáveis estudadas foi obtida através do procedimento PROC CORR do programa Statistical Analysis System ${ }^{\circledR}$ versão 9.1.3 (SAS, 2004), utilizando dez amostragens com cinco repetições de ambos ecótipos. Através da matriz de correlação simples procedeu-se a análise de trilha propriamente dita, utilizando o aplicativo computacional GENES versão 2007.0.0 (Cruz, 2007).

\section{Resultados e Discussão}

As variáveis apresentaram correlações positivas e negativas com o rendimento de sementes em $P$. notatum, portanto influenciaram de algum modo a expressão dessa variável (Tabela 1 ).

A variável que mais se correlacionou com o rendimento de sementes foi o número de perfilhos reprodutivos. O número de perfilhos reprodutivos por unidade de área é um dos componentes mais importantes e determinantes da produtividade de sementes em gramíneas forrageiras (Andrade, 1999). Segundo Souza (2001), a maior produção de perfilhos reprodutivos implica em maior número de inflorescências e, conseqüentemente, maior rendimento final de sementes. Contudo, dentro de cada espécie ou cultivar, esta característica é altamente influenciada por práticas de manejo agronômico como número, época, altura de cortes e, principalmente, época e quantidade de adubo aplicado.

Outras correlações de interesse mostraram-se significativas, por exemplo: número de perfilhos vegetativos $\times$ rendimento de sementes, cujo coeficiente foi negativo $(\mathrm{r}=-0,83)$. $\mathrm{O}$ afilhamento em gramíneas perenes se dá de forma contínua ao longo do ciclo da planta, porém, variável quanto à intensidade de aparecimento dos afilhos em função das estações de crescimento. A passagem do estádio vegetativo para reprodutivo não é sincronizada, pois na mesma planta "mãe” existe uma hierarquia entre os perfilhos que escalona o surgimento de inflorescências. Logo, em uma mesma planta existe a partição

Tabela 1 - Correlações simples entre as variáveis avaliadas

\begin{tabular}{lcccccc}
\hline & PV & PR & NRI & NSI & PMS & REND \\
\hline PV & - & $-0,83^{* *}$ & $-0,41$ & $-0,15$ & $-0,54^{*}$ & $-0,83^{* *}$ \\
PR & & - & 0,44 & 0,29 & 0,39 & $0,94^{* *}$ \\
NRI & & & - & $0,79^{* *}$ & $-0,24$ & 0,46 \\
NSI & & & & - & & 0,18 \\
PMS & & & & & - & $0,58^{*}$ \\
REND & & & & & & - \\
\hline
\end{tabular}

PV - número de perfilhos vegetativos; PR - número de perfilhos reprodutivos; NRI - número de racemos por inflorescências; NSI - número de sementes por inflorescência; PMS - peso de 1000-sementes; REND - rendimento de sementes. ** Significativo a $\mathrm{P}<0,01$ pelo teste $\mathrm{t}$

*Significativo a $\mathrm{P}<0,05$ pelo teste $\mathrm{t}$. de assimilados entre os perfilhos em elongação (reprodutivos) e aqueles mais jovens em desenvolvimento (vegetativos), influenciando negativamente o rendimento de sementes.

A elucidação da dinâmica de perfilhamento de espécies forrageiras nativas, relacionada ao rendimento de sementes, parece ser o caminho mais curto e promissor para se obter resultados mais efetivos sobre o baixo rendimento de sementes em gramíneas forrageiras. O estudo de correlações simples entre caracteres não permite tirar conclusões sobre o estudo da relação de causa/efeito, pois a correlação é apenas uma medida de associação (Vencovsky \& Barriga, 1992).

Se todas essas variáveis influenciaram o rendimento de sementes, e algumas delas apresentaram fortes correlações entre si, pode-se inferir que ocorre um sistema de interrelações entre essas características, sendo que determinada variável poderia interferir no rendimento de sementes através de outra característica correlacionada. O detalhamento dessa ocorrência e de como isso poderia acontecer é dado pela análise de trilha (Figura 2).

Pela decomposição do coeficiente de correlação linear em efeitos direto e indireto (Tabela 2), observou-se forte associação entre o número de perfilhos reprodutivos e o rendimento de sementes, cujos coeficientes lineares e de efeito direto são positivos e altamente significativos ( $r=0,82$ e $r=0,94$, respectivamente). De acordo com Vencovsky \& Barriga (1992), deve-se considerar que, quando o coeficiente de correlação e o efeito direto forem semelhantes, em magnitude e sinal, essa correlação direta explica a verdadeira associação entre as variáveis. Isso demonstra que, aparentemente, essa variável atua com maior independência em relação às demais. Desse modo, para se elevar a produção de sementes deve-se otimizar a variável número de perfilhos reprodutivos, cuidando, porém, para manter sob controle as demais variáveis. Caso contrário, poderia ter reflexos negativos no rendimento de sementes.

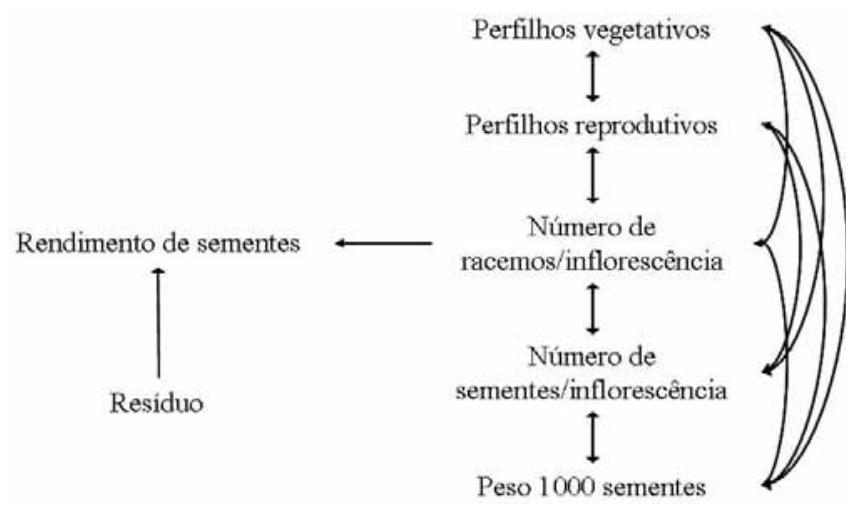

Figura 2 - Diagrama das variáveis consideradas na análise de trilha com suas interrelações. 
Tabela 2 - Resultado da análise de trilha para rendimento de sementes em $P$. notatum

\begin{tabular}{lccrrr}
\hline Item & PV & PR & NRI & NSI \\
\hline Efeito direto sobre o rendimento & 0,36 & 0,82 & $-0,44$ & 0,43 & PMS \\
Efeito indireto via PV & - & $-0,03$ & $-0,01$ & $-0,01$ & $-0,02$ \\
Efeito indireto via PR & $-0,68$ & - & 0,36 & 0,24 \\
Efeito indireto via NRI & 0,18 & $-0,19$ & - & $-0,35$ \\
Efeito indireto via NSI & $-0,06$ & 0,12 & 0,34 & - \\
Efeito indireto via PMS & $-0,30$ & 0,21 & 0,21 & $-0,13$ \\
Total = r & $-0,83$ & 0,94 & 0,46 & $-0,18$ \\
Coeficiente de determinação & & & & 0,58 \\
Efeito da variável residual & & & 0,94 \\
\hline
\end{tabular}

PV - número de perfilhos vegetativos; PR - número de perfilhos reprodutivos; NRI - número de racemos por inflorescências; NSI - número de sementes por inflorescência; PMS - peso de mil sementes.

Como já observado, o segundo componente com maior coeficiente linear que influenciou o rendimento de sementes foi o número de perfilhos vegetativos (Tabela 1). Conforme se observa na decomposição do coeficiente dessa variável (Tabela 2), a influência do número de perfilhos vegetativos no número de perfilhos reprodutivos, peso de mil sementes e com menor intensidade no número de sementes por inflorescência foi negativa em relação ao rendimento de sementes. O comportamento negativo indica que, para aumentar o rendimento de sementes, é necessário reduzir este componente, ou seja, maior conhecimento da espécie em relação ao manejo, visando maior uniformização dos perfilhos vegetativos para que os mesmos passem para o estádio reprodutivo de maneira mais sincronizada.

Outra técnica que visa o aumento do rendimento de sementes através do manejo da população de perfilhos é o manejo de fertilizantes. Macelis \& Oliveira (1984), em pesquisa com a espécie Brachiaria humidicola, notaram aumento significativo do número total de perfilhos e perfilhos florescidos $/ \mathrm{m}^{2}$ com o uso de fertilizantes nitrogenados. Segundo Carámbula (s.d.), inicialmente o efeito do nitrogênio é promover o aparecimento de novos perfilhos e, depois, fortalecer os já existentes. Esse maior número de perfilhos pode corresponder a maior número de “sítios” a serem ocupados pelas inflorescências (Humphreys \& Riveros, 1986).

O número de racemos por inflorescência apresentou coeficiente de correlação linear positivo em relação ao rendimento de sementes (Tabela 1 ). No entanto, seu coeficiente de efeito direto apresentou-se negativo (Tabela 2). Segundo Lorentz et al. (2006), quando o coeficiente de correlação linear é positivo, mas o efeito direto é negativo ou desprezível, a correlação será causada pelos efeitos indiretos, sendo estes considerados na análise. A análise de trilha mostrou que a mesma foi, em grande parte, explicada pelo seu efeito indireto via número de perfilhos reprodutivos $(\mathrm{r}=0,36)$, número de sementes / inflorescência $(r=0,34)$ e, consequentemente, no peso de 1000 sementes $(r=0,21)$ (Tabela 2$)$.
O melhoramento desta variável (número de racemos/ inflorescência) limita-se ao fato que, por fatores genéticos a mesma apresenta dois a três racemos por inflorescência, variando em tamanho de acordo com o ecótipo. Segundo McCarty et al. (2001), a espécie P. notatum normalmente apresenta inflorescências que terminam em duas ramificações, raramente três. Esta espécie pode apresentar dois a três ramos unilaterais espiciformes ascendentes conjugados ou subconjugados, variando de 5,0-13,5 cm de comprimento em cada inflorescência (Canto-Dorow et al., 1996).

A decomposição do coeficiente de correlação simples, na variável número de sementes/inflorescência, comprova que o valor de $r=0,18$ (Tabela 1 ) é influenciado pelos efeitos indiretos do número de racemos/inflorescência e peso de mil sementes (Tabela 2).

Como discutido anteriormente, o número de racemos/ inflorescência é uma variável limitada de duas a três ramificações por inflorescência. No entanto, o tamanho final das sementes é influenciado pela competição de nutrientes entre as inflorescências, provavelmente, num período precoce da meiose no saco embrionário (Proctor, 1996). Nesse contexto, a competição de nutrientes também pode ser influenciada pela hierarquia de perfilhos, ou seja, perfilhos de ordens menores formam sementes mais pesadas por receberem mais assimilados. Assim, os componentes do rendimento de sementes normalmente estão negativamente relacionados, ou seja, o aumento de um pode resultar em decréscimo do outro (Almeida et al., 1998).

O número de sementes/inflorescência merece atenção, pois uma importante característica de gramíneas forrageiras é sua incapacidade de reter, por muito tempo, as sementes maduras conectadas às inflorescências. Esta ruptura ocorre após a semente haver alcançado a maturidade, ou antes, se ocorrerem estresses causados, por exemplo, por chuvas excessivas, ventos fortes, deficiências nutricionais, hídrica ou luminosa (Souza, 2001).

O peso de 1000 sementes apresentou um coeficiente de correlação linear positivo e semelhante ao coeficiente de 
efeito direto, em magnitude e sinal, demonstrando que essa correlação direta explica a verdadeira associação entre as variáveis (Tabela 2).

O peso de sementes é uma variável fundamental no processo de produção, pois pode influenciar não somente o procedimento de semeadura da pastagem, como também a qualidade das sementes; além disso, é um dos componentes do rendimento final. O resultado encontrado neste estudo está de acordo com Humphreys \& Riveros (1986) que atribuíram ao produto entre o peso das sementes, número de sementes/inflorescência e número de perfilhos reprodutivos o rendimento final de sementes de gramíneas forrageiras.

O alto coeficiente de determinação total $(r=0,94)$ associado ao efeito residual baixo $(r=0,24)$ (Tabela 2$)$ indica que os efeitos dessas variáveis (componentes do rendimento) explicam os efeitos apresentados no diagrama causal (Figura 1) adotado para o rendimento de sementes em $P$. notatum (variável básica). O coeficiente de determinação equivalente a $100 \%$ indica que as variáveis explicativas determinaram totalmente a variação da variável básica (Furtado et al., 2002).

Os resultados da análise de correlação e da análise de trilha foram muito semelhantes, ambos apontando o número de perfilhos reprodutivos como a principal variável a influenciar o rendimento de sementes em $P$. notatum. Apesar disso, ressalta-se a importância da análise de trilha pelo fato da mesma decompor a análise de correlação em efeitos diretos e indiretos, o que imprime maior segurança no momento de se eleger as características que deverão ser mais bem trabalhadas para se chegar ao objetivo final, que no caso é um maior rendimento de sementes (Montardo et al., 2003).

Maior sucesso no rendimento de sementes e ressemeadura natural pode ser alcançado se forem concentrados esforços, tanto do ponto de vista de melhoramento, quanto do ponto de vista de manejo, no período de florescimento, a fim de obter o maior número de inflorescências maduras no momento da colheita.

\section{Conclusões}

O número de perfilhos reprodutivos é a característica que mais se correlaciona com o rendimento de sementes. A emissão constante de perfilhos vegetativos influencia negativamente os demais componentes do rendimento de sementes. A análise de trilha é um procedimento útil, preciso e de fácil aplicação no detalhamento das correlações entre as variáveis estudadas.

\section{Referências}

ABBOTT, L.A.; PISTORALE, S.M.; FILIPPINI, O.S. Path coefficient analysis for seed yield in Bromus catharticus. Ciencia y Investigación Agraria, v.34, n.2, p.107-114, 2007.

ADENIJI, O.T. Step wise regression and path analysis of dry matter accumulation in the vegetative and reproduction parts of soybeans (Glycine max [L.] Merr.). Agricultural Journal, v.2, n.1, p.697-701, 2007.

ALMEIDA, M.L.; MUNDSTOCK, C.M.; SANGOI, L. Conceito de ideotipo e seu uso no aumento do rendimento potencial de cereais. Ciência Rural, v.28, n.2, p.325-332, 1998.

ANDRADE, R.P. Situação atual e perspectivas da produção e pesquisa em sementes de forrageiras tropicais. Planaltina: EMBRAPA Cerrados, 1999. 28p. (Documentos, 11).

AYCICEK, M.; YILDIRIM, T. Path coefficient analysis of yield and yield components in bread wheat (Triticum aestivum L.) genotypes. Pakistan Journal Botany, v.38, n.2, p.417-424, 2006.

BABAR, M.; KHAN, A.A.; ARIF, A. et al. Path analysis of some leaf and panicle traits affecting grain yield in doubled haploid lines of rice (Oriza sativa L.). Journal of Agricultural Research, v.45, n.4, p.245-252, 2007.

BERGAMASCHI, H. Clima da estação experimental da UFRGS (e região de abrangência). Porto Alegre: UFRGS, 2003. 78p.

CANTO-DOROW, T.S.; LONGHI-WAGNER, H.M.; VALLS, J.F.M. Revisão taxonômica das espécies de Paspalum grupo Notata (Poaceae - Paniceae) do Rio Grande do Sul, Brasil. Iheringia, v.47, p.3-44, 1996.

CARÁmbula, M. Producción de semillas de plantas forrajeras. Montevideo: Hemisferio Sur, [s.d.]. 518p.

CARVALHO, C.G.P.; ARIAS, C.A.A.; TOLEDO, J.F.F. et al. Correlação e análise de trilha em linhagens de soja semeadas em diferentes épocas. Pesquisa Agropecuária Brasileira, v.37, n.3, p.311-320, 2002.

CECATO, U.; MACHADO, A.O.; MARTINS, E.N. et al. Avaliação da produção e algumas características da rebrota de cultivares e acessos de Panicum maximum Jacques sob duas alturas de corte. Revista Brasileira de Zootecnia, v.29, n.3, p.660-668, 2000.

COIMBRA, J.L.M.; GUIDOLIN, A.F.; ALMEIDA, M.L. et al. Análise de trilha dos componentes do rendimento de grãos em genótipos de canola. Ciência Rural, v.34, n.5, p.1421-1428, 2004.

CRUZ, C.D. Programa Genes: Versão Windows; aplicativo computacional em genética e estatística. Viçosa, MG: Universidade Federal de Viçosa, 2007. (CD-ROM).

CRUZ, C.D. Programa Genes: estatística experimental e matrizes. Viçosa, MG: Editora UFV, 2006. 285p.

FURTADO, M.R.; CRUZ, C.D.; CARDOSO, A.A et al. Análise de trilha do rendimento do feijoeiro e seus componentes primários em monocultivo e em consórcio com a cultura do milho. Ciência Rural, v.32, n.2, p.217-220, 2002.

HUMPHREYS, L.R.; RIVEROS, F. Tropical pasture seed production, plant production and protection. Roma: FAO, 1986. 203p. (Paper, 8).

KUREK, A.J.; CARVALHO, F.I.F; ASSMANN, I.C. et al. Análise de trilha como critério de seleção indireta para rendimento de grãos em feijão. Revista Brasileira de Agrociência, v.7, n.1, p.29-32, 2001.

LORENTZ, L.H.; FORTES, F.O.; LÚCIO, A.D. Análise de trilha entre as variáveis das análises de sementes de espécies florestais exóticas do Rio Grande do Sul. Revista Árvore, v.30, n.4, p.567-574, 2006.

MACELLIS, N.; OLIVEIRA, P.R.P. Componentes da produção de sementes de Brachiaria humidicola: efeito da adubação nitrogenada e épocas de colheita. Zootecnia, v.22, n.1, p.57-71, 1984.

McCARTY, L.B.; EVEREST, J.W.; HALL, D.W. et al. Color atlas of turfgrass weeds. Chelsea: Ann Arbor Press, 2001. 59p.

MONTARDO, D.P.; DALL'AGNOL, M.; CRUSIUS, A.F. et al. Análise de trilha para rendimento de sementes em trevo 
vermelho (Trifolium pratense L.). Revista Brasileira de Zootecnia, v.32, n.5, p.1076-1082, 2003.

PROCTOR, P.J. The natural history of pollination. 5.ed. London: [s.n], 1996. 463p.

SENGUL, S. Using path analysis to determine Lucerne (Medicago sativa L.) seed yield and its components. New Zealand Journal of Agricultural Research, v.49, n.1, p.107-115, 2006.

SILVA, M.A.; LIRA, M.A.; SANTOS, M.V.F. dos et al. Análise de trilha em caracteres produtivos de Pennisetum sob corte em Itaimbé, Pernambuco. Revista Brasileira de Zootecnia, v.37, n.7, p.1185-1191, 2008.

SOUZA, F.H.D. Produção de gramíneas forrageiras tropicais. São Carlos: EMBRAPA, 2001. 43p.
STATISTICAL ANALYSIS SYSTEM - SAS. SAS OnlineDoc. Version 9.1.3. Cary: SAS Institute, 2004. (CD-ROM).

STEINER, M.G. Caracterização agronômica, molecular e morfológica de acessos de Paspalum notatum Flugge e Paspalum guenoarum Arech. 2005. 137f. Dissertação (Mestrado em Zootecnia) - Faculdade de Agronomia Departamento de Plantas Forrageiras e Agrometeorologia, Universidade Federal do Rio Grande do Sul, Porto Alegre.

STRECK, E.V.; KÄMPF, N.; DALMOLIN, R.S.D. et al. Solos do Rio Grande do Sul. 2.ed. Porto Alegre: EMATER/RS, UFRGS, 2008. 222p.

VENCOVSKY, R.; BARRIGA, P. Genética biométrica no fitomelhoramento. Ribeirão Preto: Revista Brasileira de Genética, 1992. 496p. 